\title{
Representation of background error standard deviations in a limited area model data assimilation system
}

\author{
By MAGNUS LINDSKOG ${ }^{1 *}$, NILS GUSTAFSSON ${ }^{1}$ and KRISTIAN S. MOGENSEN ${ }^{2} \dagger$, \\ ${ }^{1}$ Swedish Meteorological and Hydrological Institute, Folkborgsvägen 1, S-60176 Norrköping, Sweden; ${ }^{2}$ Danish \\ Meteorological Institute, Lyngbyvej 100, DK-2100, Copenhagen, Denmark
}

(Manuscript received 20 October 2005; in final form 14 March 2006)

\begin{abstract}
Two different approaches for improving the representation of background error standard deviations have been developed and introduced into the HIRLAM high-resolution limited area model 3-D variational data assimilation scheme. One of the methods utilizes a horizontally varying climatological background error standard deviation field, estimated from a time-series of innovations. The second approach attempts to take temporal and spatial variations of the background error standard deviations into account by applying an Eady instability measure to the background field. The two approaches are described in detail and their functionality is demonstrated. Parallel data assimilation and forecasts experiments indicate a slightly positive impact on average verification scores, and in addition a positive impact is demonstrated for an individual synoptically active case.
\end{abstract}

\section{Introduction}

Data assimilation in numerical weather prediction (NWP) optimally blends observations with atmospheric model data in order to obtain the best possible model initial state. The number of observations is generally small compared to the number of degrees of freedom in the initial state of the forecast model. This problem is overcome by introducing a priori information. The a priori information is in the form of a model background state, usually a short-range forecast, supplemented with statistical information about its errors, in addition to statistical information about the observation errors.

One approach to estimate background error covariances is to derive these from statistics of innovation vectors (differences between observed values and the corresponding background state equivalents), under the assumption that the spatial structures of the observation errors are known (Hollingsworth and Lönnberg, 1986) and also under assumptions on dynamical balances between different variables. Another frequently applied approach is to consider statistics of forecast differences as an ap-

\footnotetext{
* Corresponding author. e-mail: magnus.lindskog@smhi.se $\dagger$ Present affiliation: European Centre for Medium-Range Weather Forecasts, Shinfield Park, Reading RG2 9AX, UK.

DOI: $10.1111 /$ j.1600-0870.2006.00190.x
}

proximation to the forecast error covariances. This corresponds for instance to 'the NMC method' (Parrish and Derber, 1992; Rabier et al., 1998). Standard deviations of the forecast differences are usually rescaled to match the amplitude of $6 \mathrm{hr}$ forecast errors (Parrish and Derber, 1992; Rabier et al., 1998; Desroziers and Ivanov, 2001). The theoretical justification of 'the NMC method' is rather weak and its main assumptions and characteristics have been discussed by Bouttier (1996) and Berre (2000). An interesting alternative is to derive the forecast error covariances from ensemble assimilation experiments (Houtekamer et al., 1996) by perturbing, for example, observations and forecast model parameterizations. Another method could be to use the time-averaged covariances of an extended Kalman filter (EKF), applied in research mode, to specify the static error covariances (Bouttier, 1996), although this is much more costly. Different Kalman filter-based techniques have been used to obtain synoptically dependent background characteristics of error covariances, such as the reduced rank Kalman filter (RRKF), as proposed by Fisher (1998), and the ensemble Kalman filter (Houtekamer and Mitchell, 1998; Evensen, 2003). An alternative approach is based on maximum likelihood theory and fitting of a covariance model to innovation vectors (Dee, 1995).

It is possible to consider the flow dependency of the background error standard deviations only, assuming the error correlations to be stationary. This has, for example, been utilized to propagate estimated information concerning analysis error 
standard deviations from the previous analysis cycle forward in time (Fisher, 1996). This can be achieved either by applying a relatively simple error growth model (Savijärvi, 1995) or by a tangent linear version of the full, non-linear forecast model (Andersson and Fisher, 1998).

Improvements in the representation of background error standard deviations in the 3-D variational assimilation (3D-Var) scheme developed for the HIgh-Resolution Limited Area Model (HIRLAM) forecasting system (Undén et al., 2002) are described and discussed in this paper. These improvements include a more general representation of the horizontal variations of the background error standard deviations, either through a static climatological index field, as estimated from time-series of innovation vectors, or through a synoptically varying index field, based on the baroclinic instability ideas of Eady (1949). The Eady index has been designed to provide a measure of baroclinic maximum normal mode growth rate (e.g. see Lindzen and Farell, 1980; Hoskins and Valdes, 1990) and can easily be calculated from the atmospheric wind shear, static stability and the local value of the Coriolis parameter. It seems reasonable to assume that areas of large error growth rates are associated with increased background error uncertainty. We furthermore assume that the areas of error growth are well captured by the Eady instability measure so that the variations of the background error standard deviations in space and time can be based on the Eady index. The ability of the Eady index to represent the areas of high error growth is supported by the fact that the geographical positions of areas with high error growth potential as pointed out by the Eady index and by leading singular vectors, respectively, have been observed to roughly coincide (Buizza and Palmer, 1995). The two methodologies are different in that the Eady index diagnoses the instant normal mode error growth at one particular time while singular vectors provides a measure of the error growth within a given time period of typically half a day.

The paper is organized as follows: In Section 2 the basics of the HIRLAM 3D-Var is outlined, followed by a description of the two different methods for improving the representation of the background error standard deviations in Section 3. The meteorological impact of the improved background error representation is investigated in Section 4, through extended forecasts and assimilation experiments, and finally conclusions are presented in Section 5.

\section{HIRLAM 3D-Var}

The HIRLAM 3D-Var (Gustafsson et al., 2001) follows the incremental formulation (Courtier et al., 1994) and the assimilation consists of minimizing the cost function

$$
\begin{aligned}
J=J_{b}+J_{o}= & \frac{1}{2} \delta \mathbf{x}^{T} \mathbf{B}^{-1} \delta \mathbf{x} \\
& +\frac{1}{2}\left(H \mathbf{x}^{\mathbf{b}}+\mathbf{H} \delta \mathbf{x}-\mathbf{y}\right)^{T} \mathbf{R}^{-\mathbf{1}}\left(H \mathbf{x}^{\mathbf{b}}+\mathbf{H} \delta \mathbf{x}-\mathbf{y}\right)
\end{aligned}
$$

with respect to the assimilation increment vector $\delta \mathbf{x}$. Here $J_{b}$ measures the distance of the analysis (the assimilation model state) $\mathbf{x}=\mathbf{x}^{\mathrm{b}}+\delta \mathbf{x}$ to a background model state $\mathbf{x}^{\mathrm{b}}$ and $J_{o}$ measures the distance to the observations $\mathbf{y}$. The non-linear observation operator $H$ and the tangent-linear observation operator $\mathbf{H}$ projects the background state and the assimilation increments, respectively, into the observation space. $\mathbf{B}$ and $\mathbf{R}$ are the covariance matrices for the background errors and the observation errors, respectively. Furthermore, the transpose is denoted by $T$. For HIRLAM, the model state increment vector $\delta \mathbf{x}$ includes the horizontal wind components, the temperature, the specific humidity and the logarithm of surface pressure.

The background error statistics are derived from 'the NMC method' with a non-separable approach, that is, the vertical variability of the horizontal correlations and the dependency of the vertical correlations on the horizontal scale are represented.

The dynamical couplings embedded in the background error constraint are based on hydrostatic and geostrophic assumptions in order to calculate geostrophic wind increments from temperature and surface pressure increments. The ageostrophic wind increment is taken into account, and the corresponding background errors are assumed to be uncorrelated with the background errors of mass and geostrophic wind. The humidity is treated in a univariate way, with exception for a weak coupling with the wind via the hydrostatic equation (which involves virtual temperature). A more comprehensive description of the general formulation of HIRLAM 3D-Var and its background error constraint is given in Gustafsson et al. (2001).

The background error standard deviations $\sigma_{b}$ of the control variables are represented in this paper by the following expression:

$$
\begin{aligned}
& \sigma_{b}(\text { var }, p, \text { month }, \lambda, \phi, t) \\
& \quad=\sigma_{b}^{N M C}(\text { var }, p) s c a(\text { month }) I(\lambda, \phi, t)
\end{aligned}
$$

where $\sigma_{b}^{N M C}$ are the horizontally averaged background error standard deviations calculated from historical HIRLAM forecasts with 'the NMC method' for each type of control variable (var) and vertical level $(p)$. sca is an empirically determined scaling coefficient having a weak monthly dependence, representing, for example, the stronger synoptical activity during winter than during summer periods. The scaling factor $s c a$ has been tuned from statistics of innovation $\left(\boldsymbol{y}-H \boldsymbol{x}^{b}\right)$ data over the data dense European continental area. $I$ is an index field, with a spatial mean equal to 1 over the same data dense European continental area, representing latitudinal $(\lambda)$ and longitudinal $(\phi)$ variations at a particular time $t$. Note that the index field is applied to the assimilation control variables, that is, to the temperature, surface pressure, ageostrophic wind component and specific humidity increments, in the HIRLAM 3D-Var. Via the geostrophic wind balance relation it also influences the geostrophic wind increments, and this enforces some restrictions on the variability of the index field that are further discussed in Section 3.2 below. 

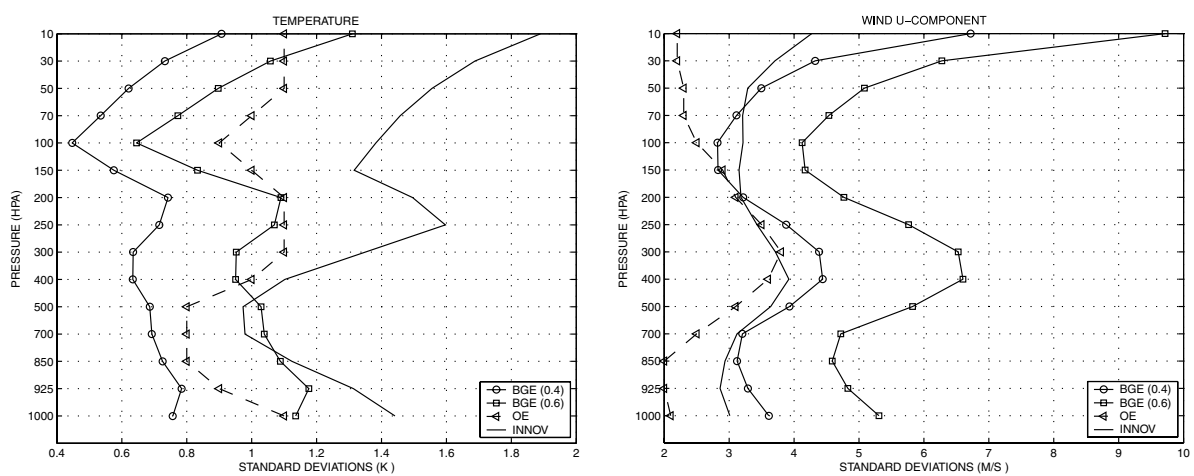

Fig. 1. Standard deviations of background errors based on 'the NMC method' (full line with boxes for 0.6 scaling and full line with circles for 0.4 scaling), of observation errors (dashed line with triangles) and of 1 year (1 June 2004-31 May 2005) of radiosonde operational innovation data (full line) from SMHI. Left panel is for temperature $(K)$ and right panel is for $u$ wind component $\left(\mathrm{m} \mathrm{s}^{-1}\right)$.
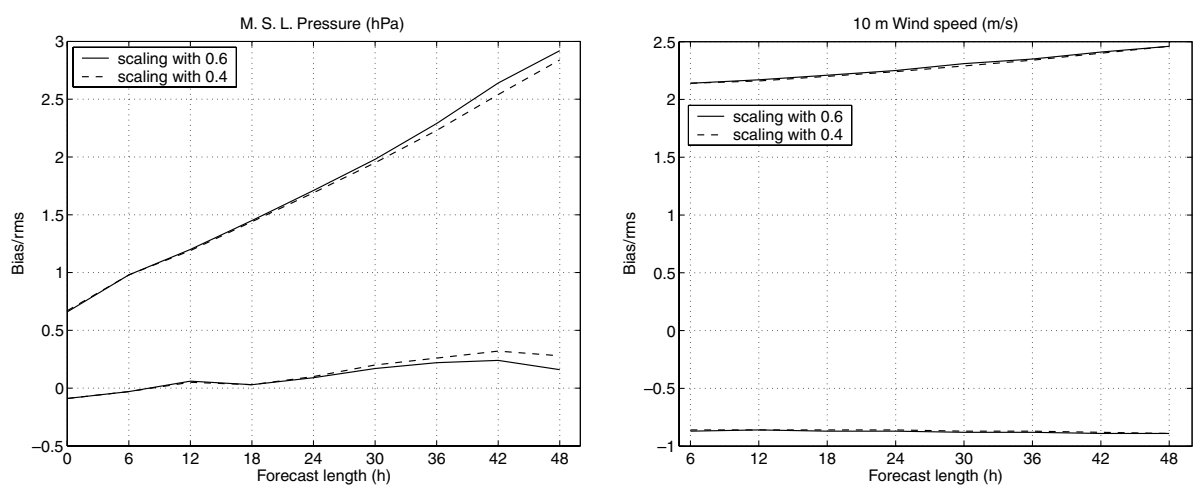

Fig. 2. Average bias and rms scores for a 1 month period (1-31 January, 2002) $P_{\mathrm{msl}}$ (left) and $W_{10 \mathrm{~m}}$ (right) forecasts as functions of forecast length (h). The $P_{\mathrm{msl}}(\mathrm{hPa})$ and $W_{10 \mathrm{~m}}\left(\mathrm{~m} \mathrm{~s}^{-1}\right)$ scores are for the experiments with scaling factors 0.4 (dashed), and 0.6 (full), respectively.

Note that the dependency of the index field on vertical level and type of variable is currently neglected.

The observation operator $H$ and the tangent-linear observation operator $\mathbf{H}$ are presently available for conventional in situ data (that is, radiosonde, PILOT wind, surface, SHIP and aircraft), TOVS (TIROS Operational Vertical Sounder) and ATOVS (Advanced TOVS) radiances, GPS (Global Positioning System) atmospheric zenith delays, GPS occultations, scatterometers, Doppler radar wind data (Lindskog et al., 2004) and MODIS wind and humidity. Bias corrections are applied to ATOVS and GPS data. The observation errors are currently assumed to be uncorrelated for all observation types. With this assumption, the covariance matrix $\mathbf{R}$ for the observation errors is diagonal and only the observation error standard deviations $\left(\sigma_{o}\right)$ need to be specified (Lindskog et al., 2001). The $J_{o}$ part of the cost function described in eq. (1) contains a variational quality control (VarQC) that accounts for non-Gaussian observation errors (Lorenc and Hammon, 1988; Ingleby and Lorenc, 1993; Andersson and Järvinen, 1999). Furthermore, before the minimization, all observations to be used are subject to screening checks, including a background check, a bad reporting practice check and a redundancy check (Lindskog et al., 2001). For the background check of non-conventional observation types a randomization technique (Andersson et al., 2000) is used for estimating the background error standard deviations in observation space. This randomization technique has been realized for one particular date, and then the corresponding results are supposed to be valid for other dates as well. In the future, the randomization may become a real time operation applied specifically for each date (e.g. to account for the flow dependent information in the observation operators and in the matrix $\mathbf{B}$ ).

\section{Background error variations}

\subsection{Tuning of the average scaling factor}

'The NMC method' background error statistics were derived from the operational application of the HIRLAM model at the Swedish Meteorological and Hydrological Institute (SMHI) during the winter 1997-1998. At this time, the HIRLAM model was applied at a horizontal resolution of $44 \mathrm{~km}$ and with 31 levels in the vertical. 'The NMC method' statistics were derived from differences between 48 and $24 \mathrm{hr}$ forecasts valid at the same time. For this operational model, and for these forecast differences, 

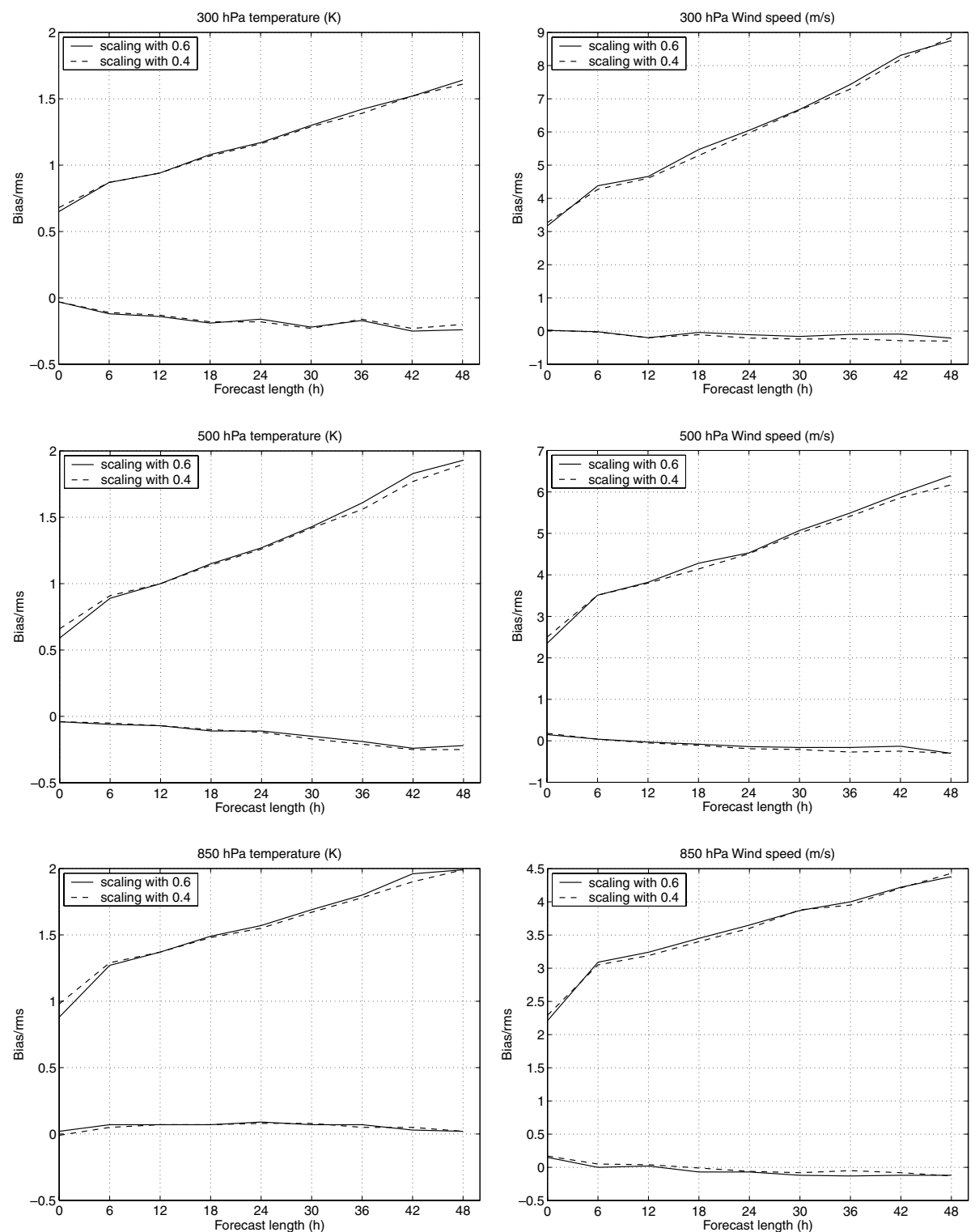

Fig. 3. Average bias and rms scores for a 1 month period (1-31 January, 2002) of forecasts, at $300 \mathrm{hPa}$ (upper), $500 \mathrm{hPa}$ (middle) and $850 \mathrm{hPa}$ (lower), as functions of forecast length $(h)$. Left column shows temperature scores $(K)$ and right column wind speed scores $\left(\mathrm{m} \mathrm{s}^{-1}\right)$. The scores are for the experiments with scaling factors 0.4 (dashed), and 0.6 (full), respectively.

an average scaling (a yearly average of the factor sca(month) in eq. 2) of 0.6 turned out to be efficient in order for the derived standard deviations to represent $6 \mathrm{hr}$ forecast background errors (Gustafsson et al., 2001). The efficiency evaluation was based on impact studies with the previous HIRLAM assimilation scheme based on Optimal Interpolation. When the same scaling factor was applied for the initial experimentation of the present study, however, it turned out that the derived background error standard deviations were too large when compared with standard deviations of operational innovation data over the data dense European area, and also too large as compared with the assumed observation error standard deviations that also should be repre- sented by the innovation statistics. This result simply reflects the improvement of operational NWP with limited area models over the period 1997-2004. Important factors that have contributed to this improvement are improved lateral boundary conditions (4/day instead of 1/day) available from the European Centre for Medium-Range Weather Forecasts (ECMWF), introduction of 3D-Var, use of ATOVS radiances, improved model physics as well as improved model resolution. A retuning of the scaling factor from 0.6 to 0.4 turned out to provide background error standard deviations more representative of current operational model data over the data dense European area as is illustrated in Fig. 1 for temperature and $\mathrm{u}$ wind component root mean square 


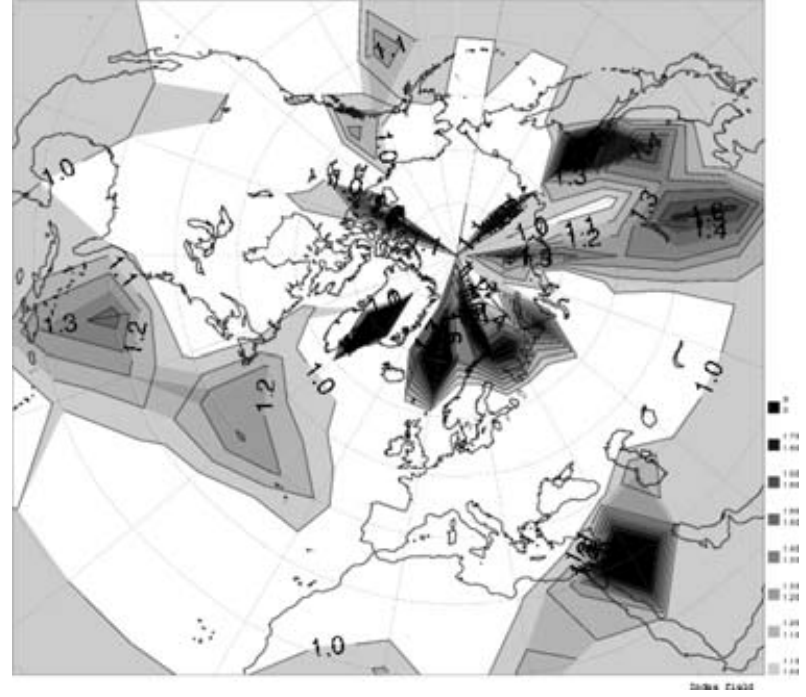

Fig. 4. Climatological index field, derived from surface pressure innovation data, before application of the horizontal filter.

error (rms) verification scores. A parallel data assimilation and forecast experiment resulted in a positive impact of changing the scaling factor from 0.6 to 0.4 . Since the scaling factor 0.4 is also more in accordance with statistics of current innovation data, it was decided to use this scaling factor for the experiments to be described in this paper. The positive impact from using the reduced scaling factor is illustrated in Figs. 2 and 3, for forecast verification scores of surface and upper air variables, respectively. It may also be noticed in Fig. 1 that, in contrast with temperature, the 0.4-scaled background error standard deviations of wind remain overestimated, as they still appear to be equal or larger than the innovation standard deviations. This may be related for instance to limitations of 'the NMC method' and/or of the current multivariate formulation. A more extended diagnosis of the relative magnitudes of background and observation error standard deviations within HIRLAM 3D-Var is currently going on. This diagnosis is based on a methodology proposed by Desroziers et al. (2005), utilizing innovations and residuals (differences between observed values and the corresponding analysed model state equivalents) from archived statistics files.

\subsection{The climatological index field}

The climatological index field was introduced with the purpose to represent horizontal variations of the background error standard deviation due to time-averaged station density and due to timeaveraged baroclinicity. It was calculated using innovations of surface pressure observations from SYNOP, SHIP and DRIBU reports. The innovations were retrieved from operational 3DVar statistics files of the Danish Meteorological Institute (DMI). Observations from the SYNOP, SHIP, DRIBU, aircraft (including AMDARS and ACARS), radiosondes and PILOT balloon reports were assimilated in DMI's operational 3D-Var analy-
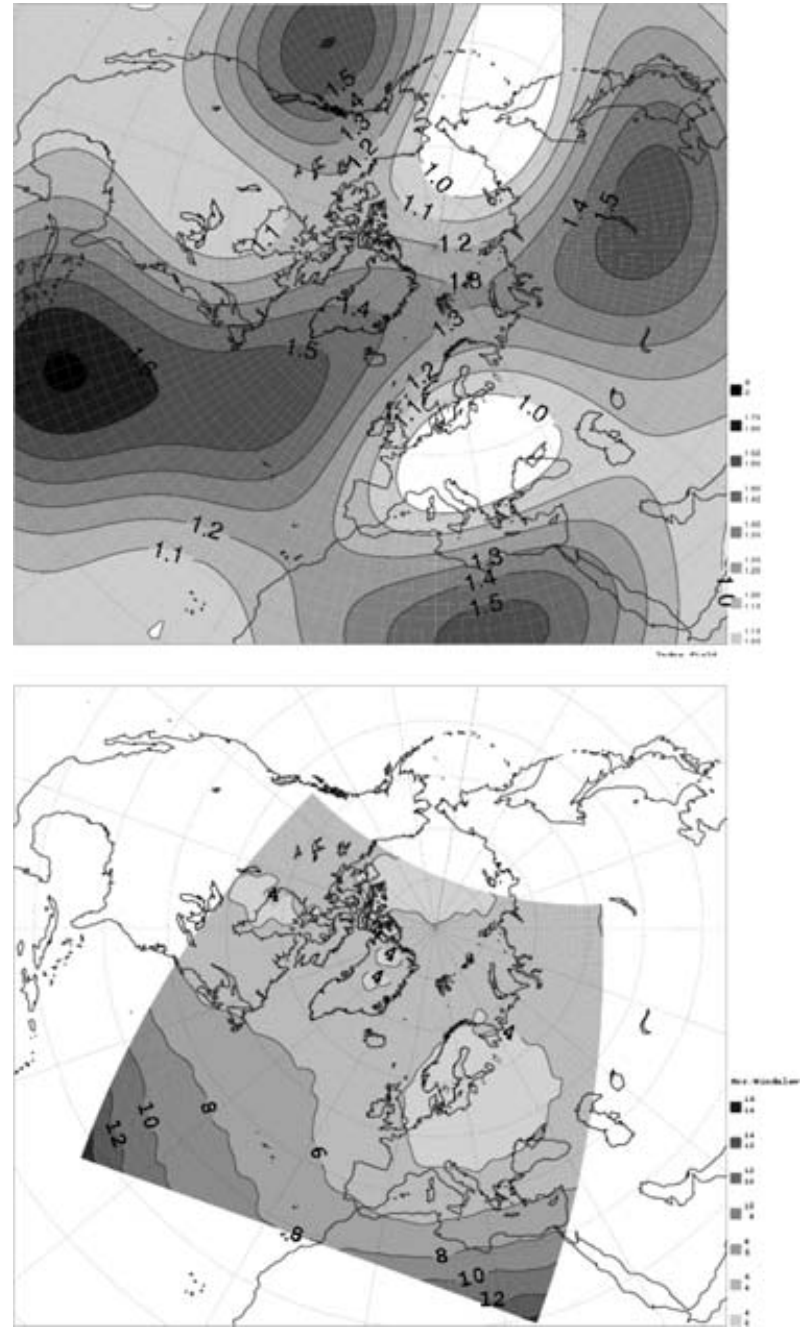

Fig. 5. Climatological index field after application of horizontal filtering excluding the tropical constraint (upper) and the corresponding background error standard deviations (in $\mathrm{m} \mathrm{s}^{-1}$ ) for the $\mathrm{u}$ wind component at model level 20 (lower, approximately $500 \mathrm{hPa}$ ). Filter coefficients of wavenumbers larger than 5 are set to zero (wavenumber 1 representing roughly the double distance between the North Pole and the equator).

ses. This means that the influence of these observations on the HIRLAM assimilation system is accounted for, when comparing the background with surface pressure observations.

Observations which passed the screening checks were selected and the square of the innovations were averaged in regular latitude-longitude boxes of $0.5^{\circ} \times 0.5^{\circ}$ size for various observation times. In order to preserve the effect of the tuning of the average background error standard deviations over the data dense European area, the resulting averaged values were normalized in such a way that the mean of the index field became 1.0 over the continental European area.

In order to avoid problems due to the uneven distribution of observations (leading to very few or even zero observations in 

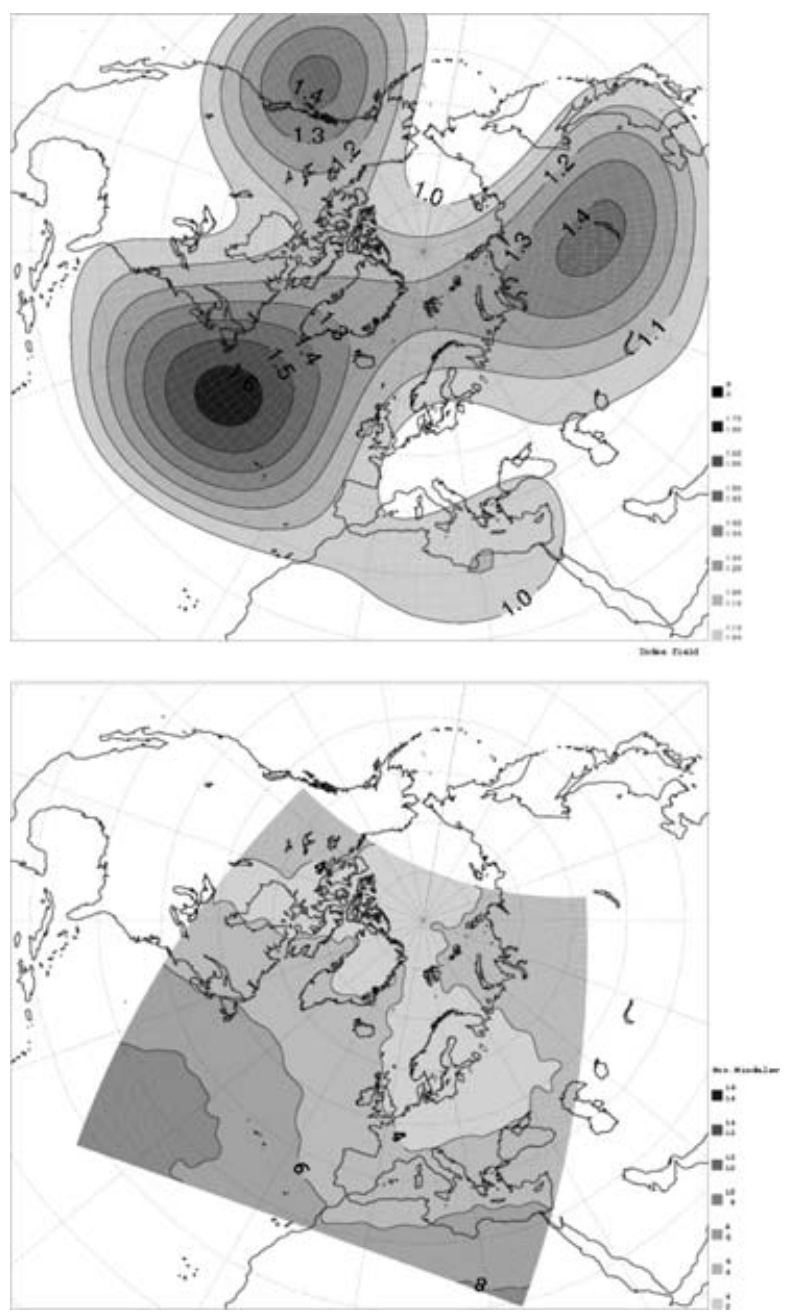

Fig. 6. Climatological index field after application of horizontal filtering including the tropical constraint (upper) and the corresponding background error standard deviations (in $\mathrm{m} \mathrm{s}^{-1}$ ) for the $\mathrm{u}$ wind component at model level 20 (lower, approximately $500 \mathrm{hPa}$ ). Filter coefficients of wave numbers larger than 5 are set to zero (wavenumber 1 representing roughly the double distance between the North Pole and the equator).

some boxes) an ad hoc horizontal filter was applied to the calculated index field. This filter was applied through the following consecutive steps: (1) Averaging over several small boxes close to the Pole due to the convergence of longitudes; (2) Elimination of box average values based on very few input data; (3) Spatial interpolation of the box values to a regular grid by successive corrections, including a particular constraint to avoid large values of the index field in tropical areas and (4) Spectral filtering. The tropical constraint was included to avoid artificial amplification of geostrophic winds due to the present simple geostrophic balance constraint in the HIRLAM 3D-Var.

The meaning of the index field is, for box values larger than 1 , that the original departures of the observations within the box were on average larger than over the data dense areas of the

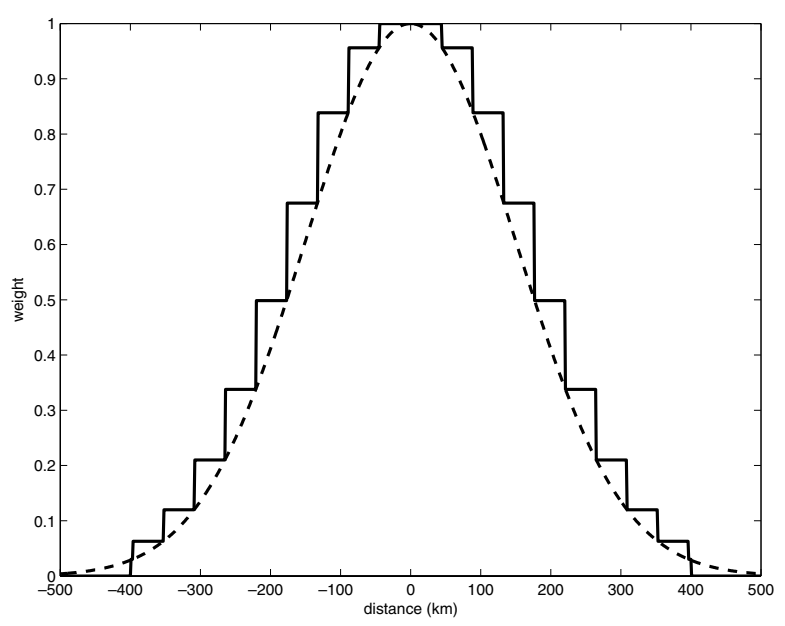

Fig. 7. Gaussian filter function applied to Eady field.

European continent. Assuming that the observation error variance is not geographically dependent, this can be interpreted as the background error on the average being large in these boxes. The geographical variations of the innovation standard deviations are likely to be smaller than the geographical variations of the background error standard deviations. As the innovation variance is the sum of the background and observation error variances, this is indeed the case if the observation error variance is uniform geographically. This effect has not been accounted for in the climatological index field.

A total of 1 year of data, from October 2000 until September 2001 , were used in order to avoid seasonal variations in the index field and to get a sufficient statistical basis for a smooth field. In the 3D-Var itself, the space-averaged seasonal variation of the background error standard deviations was accounted for by the empirical seasonal scaling factor (see eq. 2).

The normalized raw innovation data used to calculate the horizontal index field are illustrated in Fig. 4. By definition these data have an average value of 1.0 over the continental European area and similar values may be found over the data dense Northern American area. We can notice maximum values over the Northern Atlantic, over the Northern Pacific, over Northeastern Siberia and over Northeastern Africa. The data over the Arctic area are very noisy due to the small averaging boxes. Applying the horizontal filtering procedure without the tropical constraint results in the index field shown in Fig. 5 (upper). When this index field is applied to the mass field background error standard deviations, it will result in unrealistically large wind field background error standard deviations in the tropics as can be seen in Fig. 5 (lower), with values up to $14 \mathrm{~m} \mathrm{~s}^{-1}$ within the operational SMHI forecast area. These wind field background error standard deviations, here diagnosed by a randomization technique, may be considered as an artefact of a too simple background error balance constraint applied in the HIRLAM 3DVar. Other studies in the literature, indicate a decrease of wind standard deviations towards the equator (Andersson et al., 2000; Ingleby, 2001). 

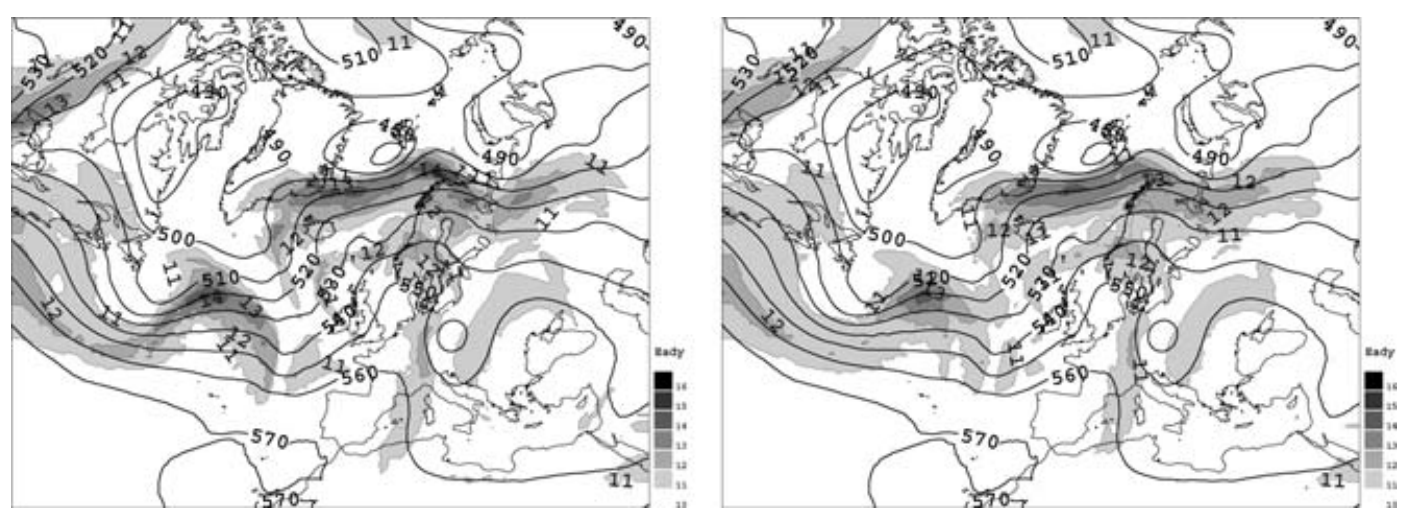

Fig. 8. Eady-based index field for 13 January 2002,0 UTC, multiplied by 10 . The contour interval is illustrated by the legend. Also shown is the 500 $\mathrm{hPa}$ geopotential height (gpm) of the background field ( $6 \mathrm{hr}$ forecast launched from 12 January 2002, $18 \mathrm{UTC}$ ). Left panel is without applied filtering and right panel with applied filtering.

Applying also the tropical filtering constraint results in systematically smaller values for the index field in the tropics, and the corresponding background error standard deviations for the wind field are more realistic, see Fig. 6.

The index field in Fig. 6, which is applied in this study, has a maximum over the Atlantic south of Greenland, where few observations were available in DMI's 3D-VAR analyses. This is also an area recognized for strong baroclinic developments (Petterssen, 1956, p. 268). As expected, minima are found over the dense conventional observation networks in Europe and North America. The index field values south of Greenland are larger by a factor 1.6 approximately than the values of the index field over Europe. It is interesting to note that the structure of the index field, as well as the relation between values over the Atlantic and over Europe, are very similar to those derived by Gustafsson (1981, p. 54) for a quasi-geostrophic three-layer model with $300 \mathrm{~km}$ horizontal resolution. The index field structures over the Northern Pacific should be interpreted with care, since the lateral boundaries of the DMI model area are situated here.

\subsection{The Eady-based index field}

To be able to represent the time-dependent variations in the increased forecast uncertainties associated with cyclone developments, spatial variations in upper air throughs, jets and thermal gradients must be utilized. One objective way of measuring these variations is to apply the so-called Eady index, based on the ideas of Eady (1949), representing the maximum normal mode error growth rate in baroclinic disturbances (Lindzen and Farell, 1980; Hoskins and Valdes, 1990):

$E=0.3125 \frac{f}{N} \frac{\mathrm{d} V}{\mathrm{~d} z}$,

where $f$ is the Coriolis parameter, $N$ the boyancy frequency, and $\frac{\mathrm{d} V}{\mathrm{~d} z}$ the vertical wind shear. The coefficient 0.3125 has been derived by analytical scaling and explicit numerical calculations, simulating the atmosphere using a quasi geostrophic model.
The Eady index approach has formed the basis for the introduction of a time-dependent variation on synoptic scales of the background error standard deviations in HIRLAM 3D-Var. It is achieved by the horizontally varying index field described in eq. (3), calculated from forecasts of previous assimilation cycles. In the HIRLAM case the vertical levels of $300 \mathrm{hPa}$ and 1000 $\mathrm{hPa}$ were used for calculating the vertical gradient of eq. (3). The local error standard deviations are assumed proportional to the error growth. To avoid too strong effects of phase errors in the background field and too strong horizontal variations, which can lead to spurious assimilation increments, a time filtering is applied such that the Eady field used in the assimilation is a weighted average of the fields within $\pm 6 \mathrm{hr}$ from the analysis time $t_{\text {an }}$ according to

$E_{t f}=0.25 E\left(t_{a n}-6\right)+0.5 E\left(t_{a n}\right)+0.25 E\left(t_{a n}+6\right)$,

where $E\left(t_{a n}-6\right), E\left(t_{a n}\right)$ and $E\left(t_{a n}+6\right)$ are the unfiltered Eady fields valid at $6 \mathrm{hr}$ before the analysis time, at the analysis time, and $6 \mathrm{hr}$ after the analysis time, respectively. These Eady fields are calculated from a $6 \mathrm{hr}$ forecast produced two assimilation cycles earlier, from a $6 \mathrm{hr}$ forecast produced one assimilation earlier and from a $12 \mathrm{hr}$ forecast produced one assimilation cycle earlier, respectively. $E_{t f}$ is the time-filtered Eady field representative at the analysis time. In addition to time filtering, a horizontal filtering is applied to the Eady field, using a Gaussian filter function, illustrated in Fig. 7.

Furthermore, a series of three normalization steps are applied: Firstly, the index field is normalized with its spatial average. Secondly, to reach maximum values around 1.6 of the Eady field (this corresponds roughly to the maximum value of the climatological index field), it is scaled with an empirically determined coefficient. Thirdly, in order not to change the background error standard deviations in areas of no baroclinic developments, index values smaller than 1 are set to 1 . The resulting index field is a synoptically varying field with a varying amplitude of the spatial variations. 

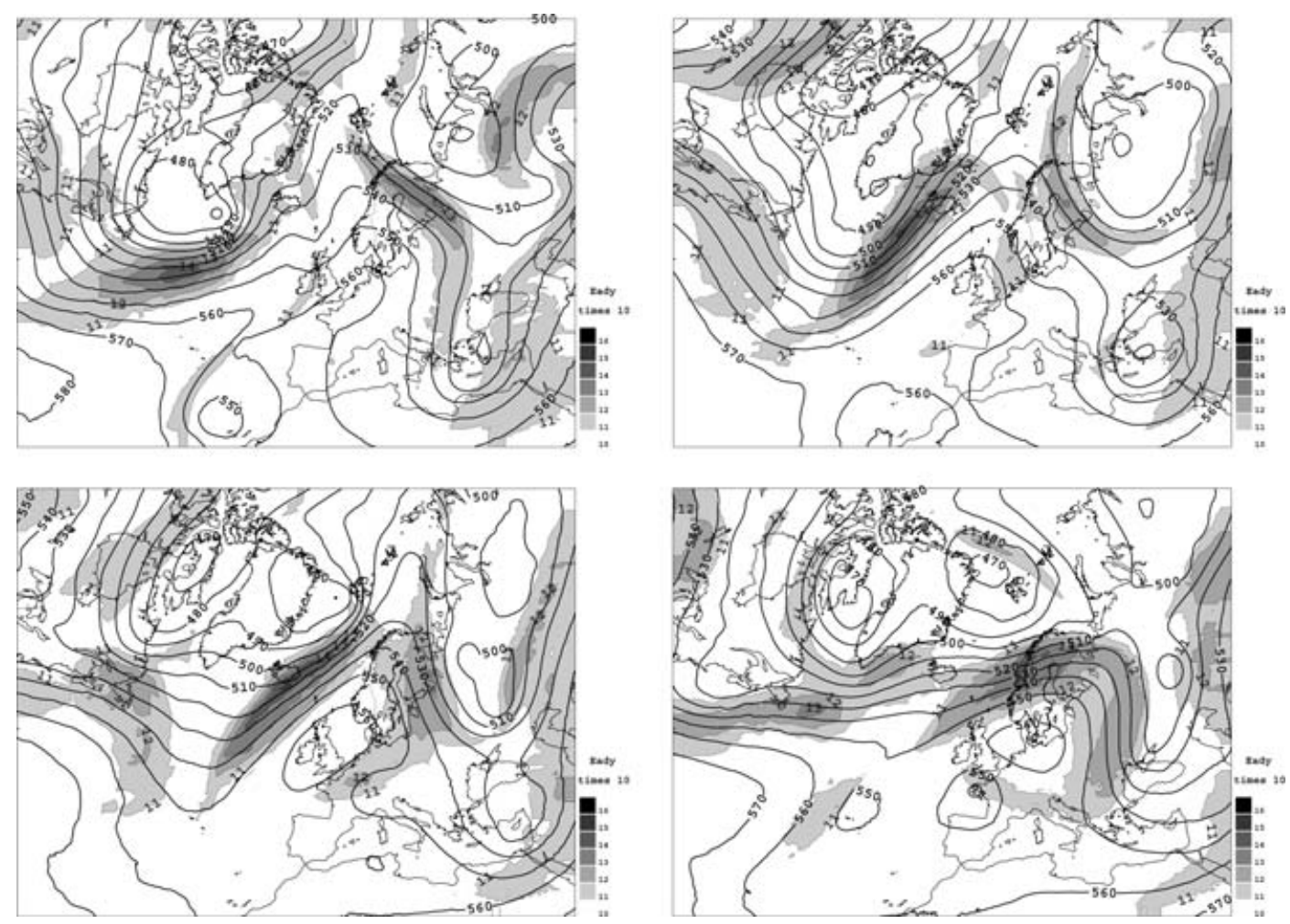

Fig. 9. Eady-based index field, multiplied by 10. The contour interval is illustrated by the legend. Also shown is the $500 \mathrm{hPa}$ geopotential height (gpm) of the background field. The fields are from 12 UTC and for four consecutive days during the one month experiment (1-31 January, 2002): 5 January (upper left), 6 January (upper right), 7 January (lower left) and 8 January (lower right).

Fig. 8 illustrates the resulting unfiltered and filtered Eady field for one particular case (13 January 2002, 0 UTC), together with the corresponding $500 \mathrm{hPa}$ geopotential height of the background field. It can be seen that areas of strong horizontal geopotential gradients, associated with increased baroclinic instability, are accompanied by larger Eady index values. The filtering is mainly due to the averaging in time and its effect is most pronounced in the area of the through, located in the Southeastern Atlantic. At present the horizontal filtering affects only wavenumbers hardly noticeable in the Figure. The choices of typical scales for the temporal and spatial filtering are rather arbitrarily chosen. In the future these can be made more objective. This may, for example, be achieved by studying statistics of phase errors in the short range prediction of cyclone positions and by relating the spatial filtering to the horizontal length scales of the structure functions.

\section{Assimilation experiments}

\subsection{Experimental design}

A 1-month data assimilation and forecast experiment, extending from 1 to 31 January, 2002, has been performed over an area covering Europe, Eastern North America, Northern Asia, Northern Africa and the Atlantic. Synoptically the selected period is active and characterized by several cyclones passing over

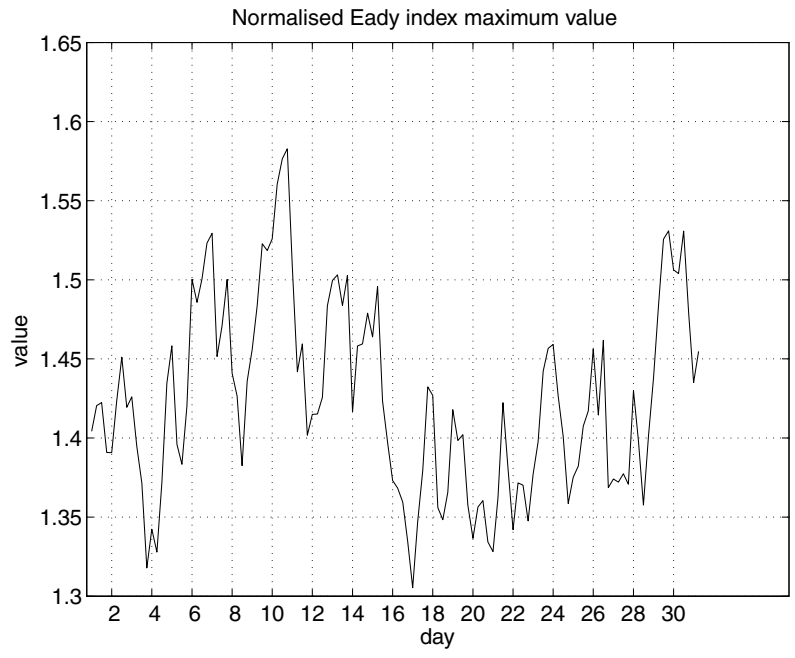

Fig. 10. Variation of normalized amplitude of Eady index field during the one month assimilation period (1-31 January, 2002).

the Northern Atlantic and through the Baltic Sea area. The model domain is illustrated in Fig. 8.

The three parallel data assimilation experiments are characterized as follows:

(1) CRL: The background error standard deviations of the control variables are independent of horizontal position. 

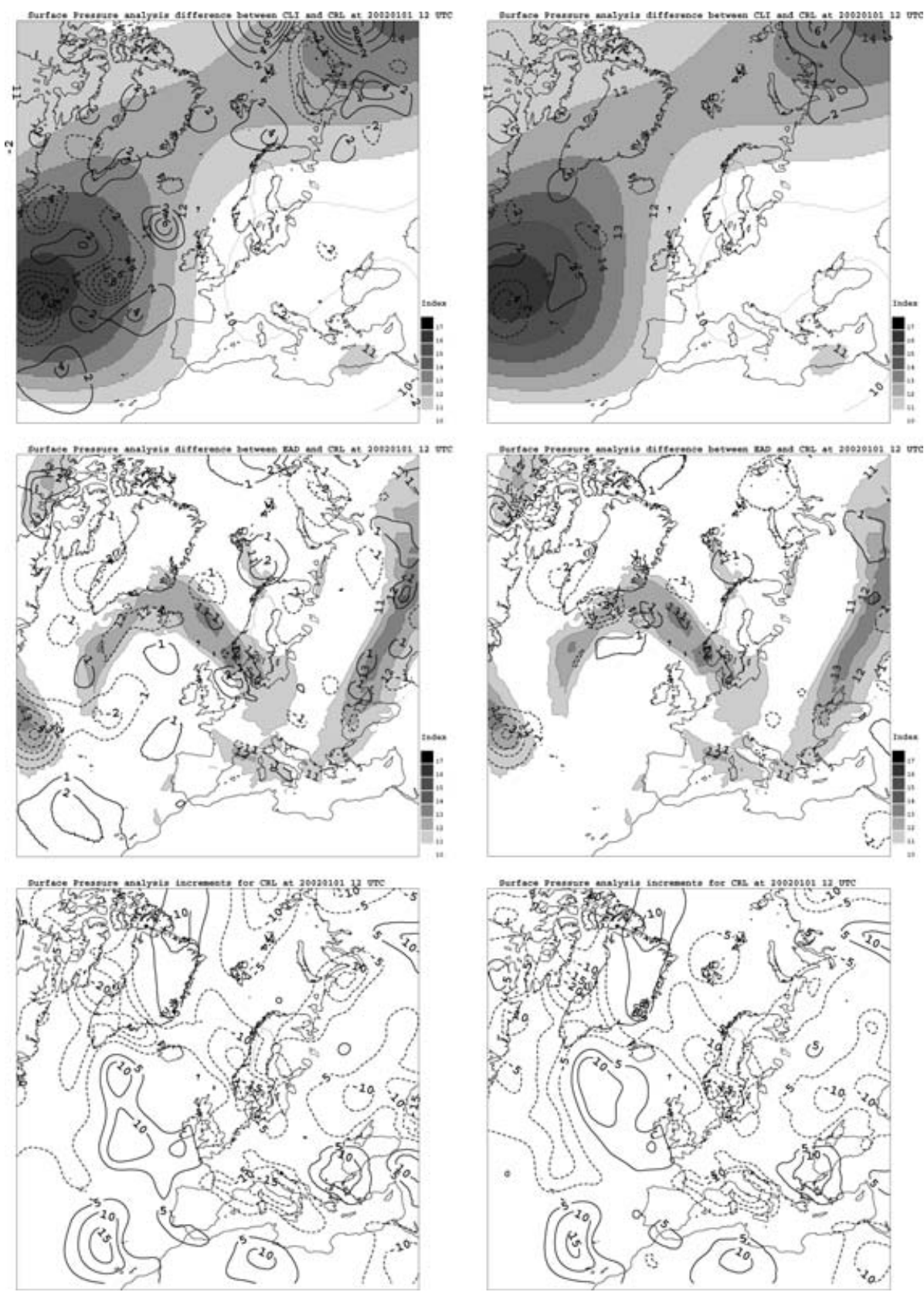

Fig. 11. Surface pressure analysis difference (contours), in tenths of $\mathrm{hPa}$, between the experiments CLI and CRL (upper panel) and between EAD and CRL (middle panel) for 1 January 2002, 12 UTC. The contour interval is $0.2 \mathrm{hPa}$. Shaded in background are the index fields, for CLI and EAD, respectively, multiplied by a factor of 10 . The lower panel shows the corresponding analysis increments for CRL, with a contour interval of $0.5 \mathrm{hPa}$. Left column when VarQC is not applied and right column when it is applied.

(2) CLI: The background error standard deviations of the control variables include a climatological index field that represents horizontal variations.

(3) EAD: The background error standard deviations of the control variables include a synoptically and horizontally varying index field that is based on Eady-instability measures.
For each of the configurations as described above, observations were assimilated in a $6 \mathrm{hr}$ assimilation cycle. Only conventional types of observations were assimilated and these were retrieved from the ECMWF archive. All observations were subject to a screening, including a background check (see Lindskog et al., 2001). For this check the same background error standard 
deviations were used for all the three assimilation experiments. After each analysis, an incremental digital filter initialisation was applied (Lynch and Huang, 1992), followed by a $48 \mathrm{hr}$ forecast. For the lateral boundary conditions, 6-12 hr old ECMWF forecasts were applied twice a day.

The experiments were run with the HIRLAM reference system (version 6.4.0) on an IBM 1600 cluster located at ECMWF, using $438 \times 336$ horizontal grid points with a resolution of $0.2^{\circ}$ and 40 vertical levels. The model physics uses a turbulence scheme based on turbulent kinetic energy (Cuxart et al., 2000). For the clouds and condensation parametrization, the STRACO scheme is applied (Sass et al., 1999). The main features of this scheme include subgrid scale condensation with a statistical distribution of cloud condensate, a smooth transition between stratiform and convective regimes and microphysics of condensation according to Sundqvist (1993). The radiation scheme is based on ideas of Savijärvi (1989). A semi-implicit and semi-Lagrangian time-integration scheme and a fourth-order implicit horizontal diffusion scheme were used in all model integrations.

To evaluate the relative quality of the analyses and subsequent forecasts of the different parallel experiments, we verified them against observations in the list of (radiosonde and SYNOP) established by the European Working Group on Limited Area Models (EWGLAM). The verification was done for weather parameters at the surface level, and for wind, temperature, humidity and geopotential at the 700 and $200 \mathrm{hPa}$ levels. The model data used in the statistics were the analyses and the $6,12,18,24,30,36$, 42 and $48 \mathrm{hr}$ forecasts.

\subsection{Temporal variations of the Eady index}

It is important that the Eady-based index field adjusts in accordance with synoptical structure variations of the background state. Fig. 9 shows the index field for four consecutive cases, separated in time by 1 day. Note how the amplitude and the structure of the index field vary and that the largest values are confined to baroclinic zones, as approximately indicated by 500 $\mathrm{hPa}$ horizontal geopotential height gradients of the corresponding background field.

Fig. 10 demonstrates the variation of the maximum normalized value of the index field within the area during the entire one month assimilation period. It can be seen that it varies between 1.3 and 1.6 and that it has a significant day-to-day variation.

\subsection{Background error implied differences}

The introduced horizontal and temporal variations of the background error standard deviations modify the analyses through possible induced differences in rejection or acceptance of observations in VarQC, as well as through the weight given to different observations. The largest impact is usually found close to the areas of modified background error standard deviation
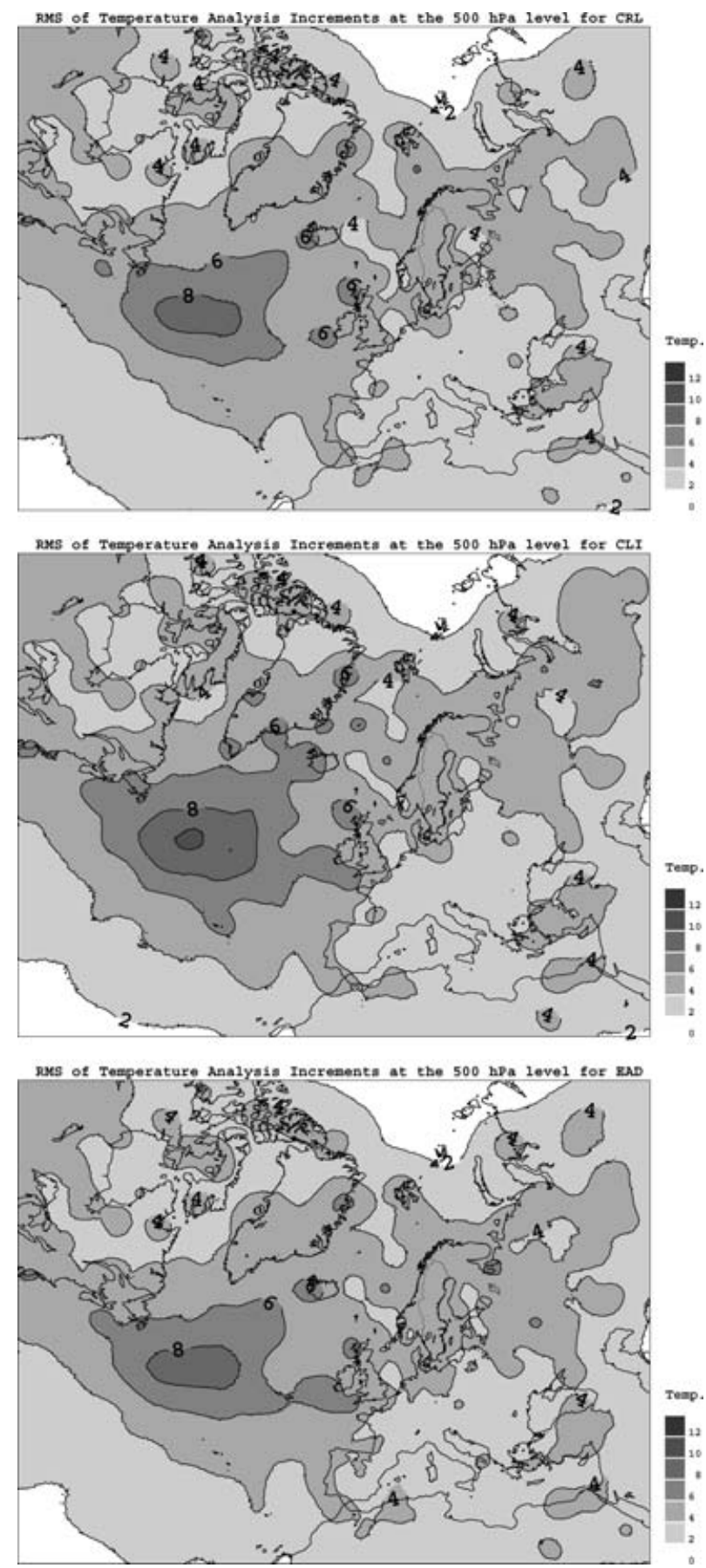

Fig. 12. Rms of the $500 \mathrm{hPa}$ temperature analysis increments $(K)$, multiplied by a factor of 10 , for the 1 month period (1-31 January, 2002). The contour interval is 2 . Upper panel is for CRL, middle for CLI and lower for EAD.

fields. However, due to the global nature of the minimization and due to effects of quality control, differences may also occur also in areas with no background error modifications. Moreover the differences in resulting analyses will lead to differences in $6 \mathrm{hr}$ forecasts. This means that the background states will be 

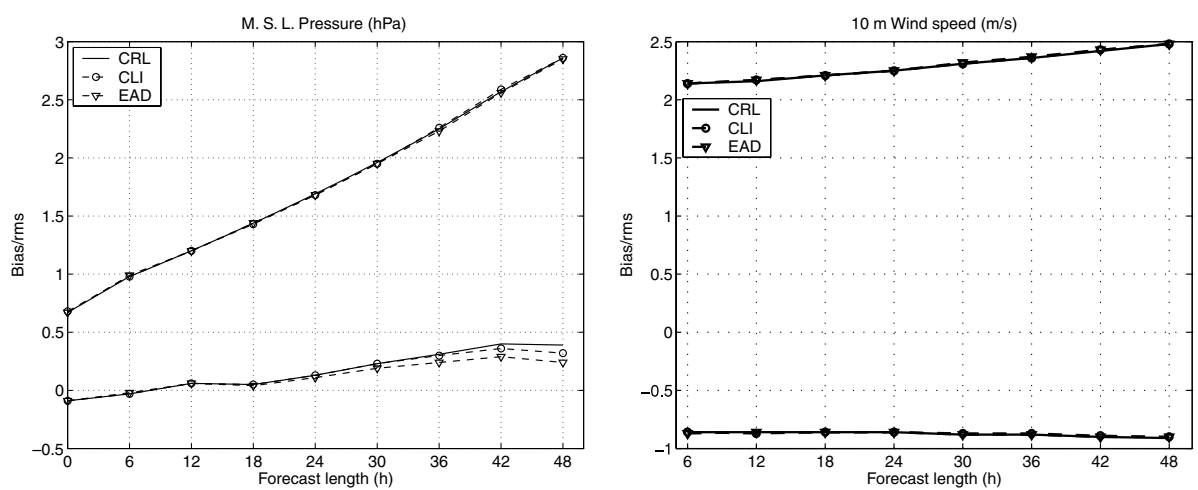

Fig. 13. Average bias and rms scores for the 1 month period (1-31 January, 2002) $P_{\mathrm{msl}}$ (left) and $W_{10 \mathrm{~m}}$ (right) forecasts as functions of forecast length $(h)$. The $P_{\mathrm{msl}}(\mathrm{hPa})$ and $W_{10 \mathrm{~m}}\left(\mathrm{~m} \mathrm{~s}^{-1}\right)$ scores are for the experiments CRL (full), CLI (dashed with circles) and EAD (dashed with triangles).

different with exception for the first assimilation cycle of the parallel run.

To demonstrate the kind of impact that differences in the background error standard deviation field can give rise to, assimilation with each of the three parallel experiment setups (CRL, CLI and EAD) were performed for one single assimilation cycle 1 January, 2002, 12 UTC. All experiments used the same background state for this demonstration. Furthermore, to investigate the effects of the VarQC, the assimilation was carried out without and with VarQC. The differences in surface pressure analyses between the two experiments with horizontally varying background errors (CLI and EAD) and the one with no variation (CRL) are shown in Fig. 11 together with the analysis increments of CRL. By comparing the analysis increments of CRL without and with VarQC applied, respectively, it can be seen that large differences are found over western Greenland, over the Southwest Atlantic and over the Barents Sea. It is obvious that the differences in the analyses are dependent on whether VarQC is applied or not. Without VarQC the analysis differences are larger. This could be qualitatively understood since the main effect of VarQC is to reject some 'critical' observations that tend to create relatively large analysis differences. In the case when VarQC is applied, the analysis differences are almost only found in areas of modified background error standard deviations, both for differences between CLI and CRL and differences between EAD and CRL. The exact positions of increments are related to locations of the observations. This explains why the largest increments are not found exactly at the local maximum values of the climatologically and Eady-based background error standard deviations. When VarQC is not applied, analysis differences also occur in areas where the background error standard deviations are only slightly or not at all modified, in particular for the differences between EAD and CRL.

The accumulated effect of the differences in the background error standard deviations on the analyses is illustrated in Fig. 12, which shows average rms of analysis increments at the $500 \mathrm{hPa}$ level for 1-31 January 2002. The largest differences between the three parallel experiments are found over the Atlantic, and the differences with CRL are larger for CLI than for EAD. In this area the rms values are higher for CLI than for CRL. The reason is the relatively larger weight given to observations in this area in the case of CLI than in the case of CRL, in combination with the low observation density. Over the rest of the area the difference in observation weighting is smaller, resulting in smaller differences. Interestingly the largest differences between EAD and CRL are found over the Atlantic, with larger EAD values. The Eady-based background error standard deviations are often larger than the CRL background error standard deviations in this area, due to high cyclone activity in the region.

\subsection{Observation verification results}

Figure 13 illustrates the time-averaged rms verification scores for mean sea-level pressure $\left(P_{\mathrm{msl}}\right)$ analyses and forecasts and for the $10 \mathrm{~m}$ wind speed $\left(W_{10 \mathrm{~m}}\right)$ forecasts, in comparison to the observations. The HIRLAM forecasts tend to have a rather small but increasingly larger positive bias in the $P_{\text {msl }}$ field with increasing forecast length, for all three experiments. For $W_{10 m}$, on the other hand, all experiments showed a negative but rather constant negative bias. The rms scores are very similar for the three different configurations, both for $P_{\mathrm{msl}}$ and $W_{10 \mathrm{~m}}$.

The time-averaged bias and rms scores for the 1 month of geopotential height, temperature and wind speed at the 700 and $200 \mathrm{hPa}$ levels are shown in Fig. 14. It can be seen that the temperature scores show a slight warming with increasing forecast length, for both vertical levels. The wind speeds on the other hand indicate a small decrease in wind speed with increasing forecast length, for both vertical levels. For both wind speeds and temperatures the magnitude of the bias is rather small. In terms of rms error the index-based geopotential height and wind-speed forecasts are better than the control forecasts. There are, however, no significant difference between the forecasts utilizing climatologically based and Eady-based index fields, respectively. For temperature, the rms scores are rather similar for all three experiments and for both vertical levels. 

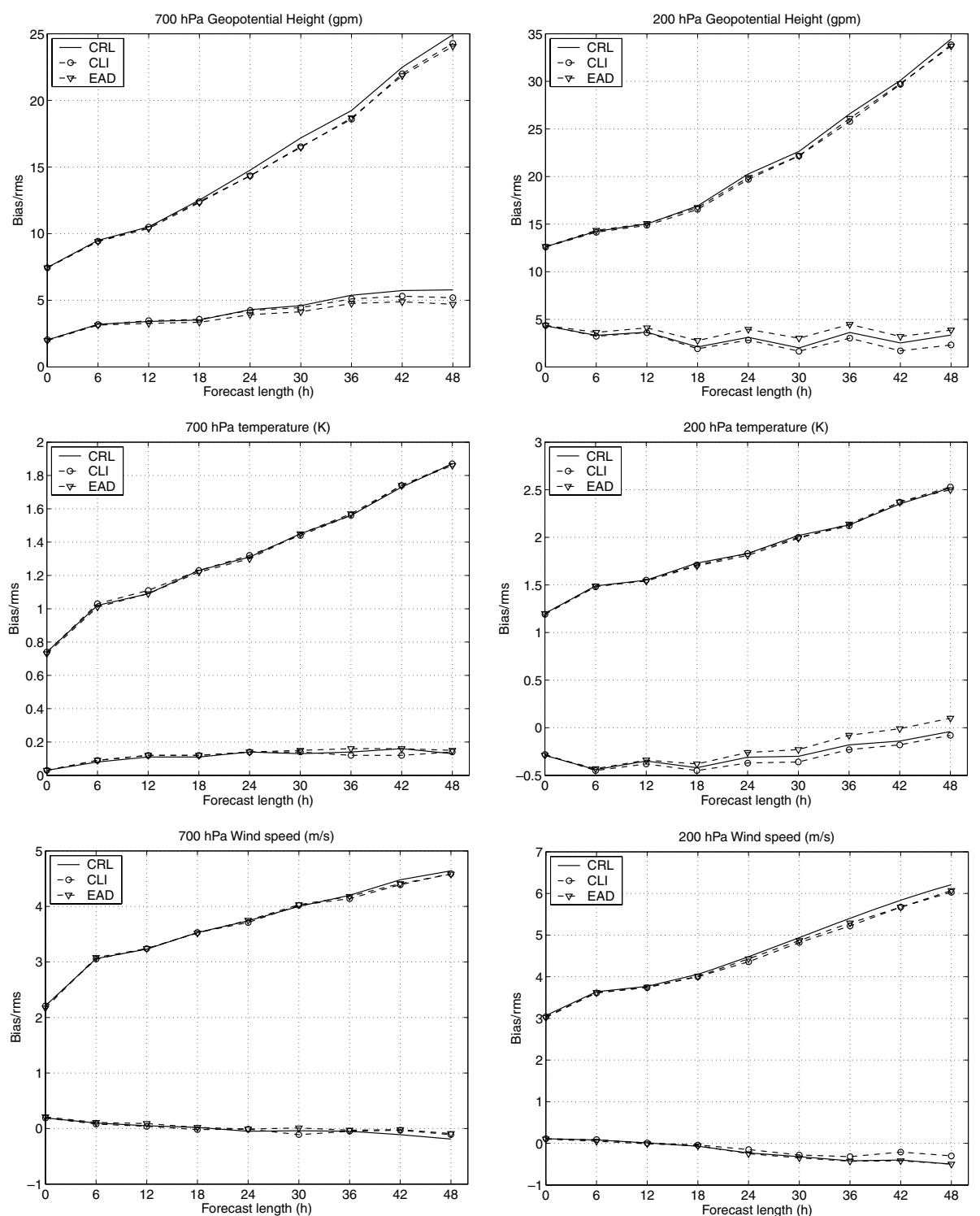

Fig. 14. Average bias and rms scores for the 1 month period (1-31 January, 2002) forecasts, at $700 \mathrm{hPa}$ (left) and $200 \mathrm{hPa}$ (right), as functions of forecast length $(h)$. Upper row shows geopotential height scores (gpm), middle row temperature scores $(K)$ and lower row wind speed scores $\left(\mathrm{m} \mathrm{s}^{-1}\right)$. The scores are for the experiments CRL (full), CLI (dashed with circles) and EAD (dashed with triangles).

For all the bias and rms scores with various assimilation configurations, as described above, a strong temporal variability in observation verification scores is seen for different model variables. As an example, Fig. 15 shows the rms values of the $48 \mathrm{hr} P_{\mathrm{msl}}$ forecasts, in comparison to verifying observations, for the entire month. The results of the three different runs are seen to outperform each other during different periods, although on average they are rather similar.

\subsection{A case study}

Since most observations used in the verification package are located over the continental Europe, the conclusions drawn from the observation verification are only valid over land. To complement the observation verification we have therefore manually verified the development and prediction of a series of lowpressure systems over the Atlantic and Northern Europe using analyses to verify forecasts.

The particular case selected is characterized by a series of cyclones intensifying and moving eastwards across the Atlantic and Northern Europe. The left panel of Fig. 16 shows the cyclone positions at 14 January 2002, 6 UTC, for the different experiments, as predicted by a $48 \mathrm{hr}$ forecast, launched from 12 January 2002, 6 UTC. The right panel shows the corresponding verifying analyses. It can be seen that the verifying analyses are rather similar, showing three low pressure systems located 


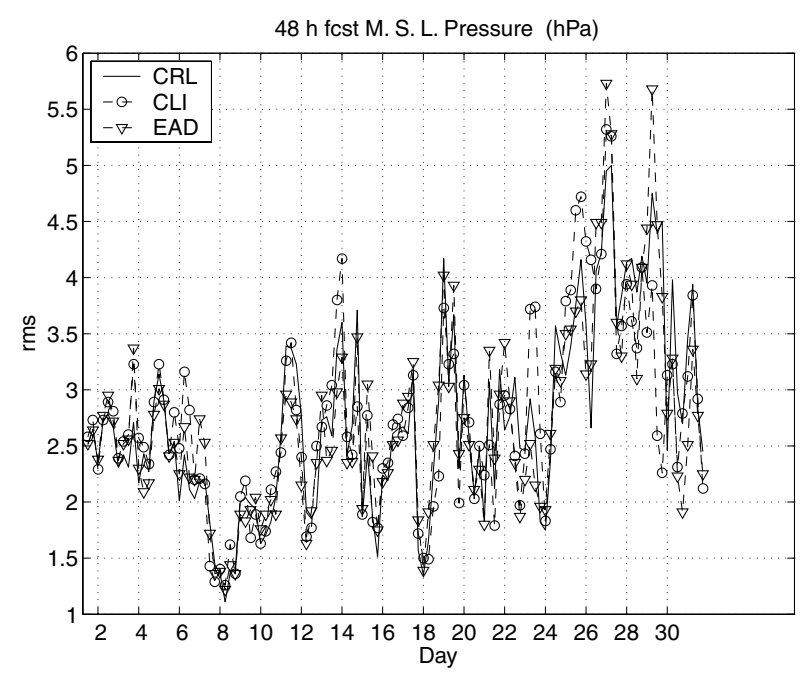

Fig. 15. Time variability of the $48 \mathrm{hr} P_{\mathrm{msl}}$ forecast rms scores (hPa) during the one month period (1-31 January, 2002). The scores are for the experiments CRL (full), CLI (dashed with circles) and EAD (dashed with triangles).

over Southeastern Canada, southwest of Iceland and north of Scandinavia, respectively. It can be seen that all the forecasts predicted the cyclone over southeastern Canada very well. Furthermore the bi-modal structure of the low pressure system southwest of Iceland was very well predicted by all forecasts. However the control forecast (upper left) heavily underestimated the depth of the low north of Scandinavia. The forecasts based on analyses utilizing the climatological (middle left) and, in particular, the Eady-based (lower left) background error standard deviation variations captured the depth considerably better (around $985 \mathrm{hPa}$ instead of $990 \mathrm{hPa}$ in the control forecast, and $980 \mathrm{hPa}$ in the analyses). All the forecasts tended to separate the single low North of Scandinavia, as represented by all three analyses, into two or three subparts (with spurious lows over continental northern Russia and near the northern Norwegian coast). This behaviour was most evident in the control forecast and less of a problem in the Eady-based forecast.

It thus seems that the improved background error representation has a positive impact on the forecast quality for the individual case selected. The slightly improved forecast obtained with the Eady index field based background errors, as compared with climatological index field, might be an indication of the importance of flow dependent background error statistics in particularly active weather situations.

\section{Conclusions and perspectives}

Two different approaches for improving the representation of background error standard deviation variations have been developed and introduced into the HIRLAM 3D-Var system. One of the methods includes a horizontally varying climatological background error standard deviation field, estimated from a timeseries of innovations. The second approach is based on timedependent background error standard deviations, estimated from Eady instability measures. In both approaches, the derived background error standard deviations were allowed to influence the 3D-Var minimization and the 3D-Var variational quality control, and not the screening of the observations. The two approaches are described and their effects on analyses and forecasts are demonstrated. Parallel assimilation and forecasts experiments reveal a slightly positive impact on average verification statistics, and a positive impact has been demonstrated for a synoptically active case.

In the short term, future work should include development of more objective filtering characteristics and scaling coefficients for the Eady-based representation of background error standard deviations. The application of climatologically based and Eadybased background error standard deviations should furthermore be applied to the screening of observations. The decisions of whether a suspicious observation should be rejected or not in the background check would most likely benefit from an improved representation of background errors. Furthermore, since some important observing systems, for example, ship and aircraft observations, provide data with preference for certain levels, it may turn out to be useful to extend the background error standard deviation index field to include also the vertical dimension. In order to obtain background error standard deviations that are dependent both of station density and synoptical situation it would in the future be interesting to combine the climatologically and Eady-based representation of background error standard deviations and to assess the meteorological impact. We also plan to adopt the climatological and Eady based representation of background errors to an improved mass-wind balance based on a statistical formulation (Berre, 2000). This would eliminate the need for a tropical constraint of the index field, as discussed above.

The present approach for representing time-dependent (or flow-dependent) background error standard deviations is associated with certain weaknesses. For example, in case the background model state is affected with significant phase error, the Eady model might provide the enhanced influence of the observations in the wrong position. One way to alleviate this would be to introduce an ensemble of forecast background states, from which a more representative estimate of the uncertainty of the baroclinic development could be derived. One may also question whether it is sufficient to introduce a flow-dependent description of the background error standard deviations only, or whether one should extend this flow-dependency to the spatial structures as described by spatial background error correlations. With this perspective, it is possible to foresee development of a synthesis of variational data assimilation and ensemble Kalman filter based data assimilation. 

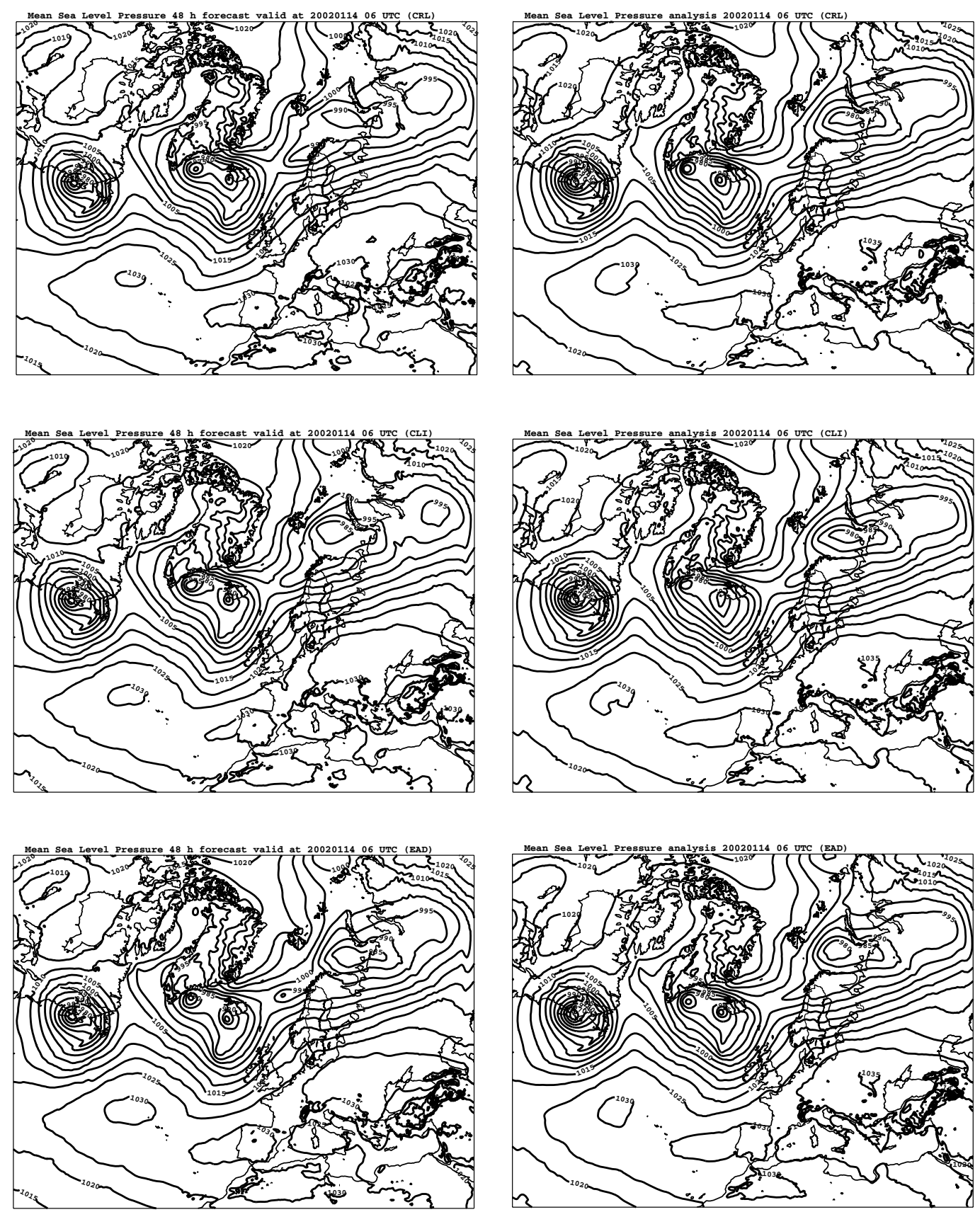

Fig. 16. Forecasts at $48 \mathrm{hr}$ (left) of $P_{\text {msl }}$, valid on 14 January 2002 at 6 UTC, and corresponding verification analyses (right). The contour interval is $5 \mathrm{hPa}$. The results are for CRL (upper), CLI (middle) and EAD (lower).

\section{Acknowledgments}

We would like to thank the reviewers for their useful comments, from which the manuscript has improved.

\section{References}

Andersson, E. and Fisher, M. 1998. Background errors for observed quantities and their propagation in time. Proceedings 1998 ECMWF workshop on diagnosis of data assimilation systems. ECMWF, Reading, UK, 81-89.

Andersson, E. and Järvinen, H. 1999. Variational quality control. Q. J. R. Meteorol. Soc. 125, 697-722.

Andersson, E., Fisher, M., Munro, R. and McNally, A. 2000. Diagnosis of background errors for radiances and other observable quantities in a variational data assimilation scheme, and the explanation of a case of poor convergence. Q. J. R. Meteorol. Soc. 126, 14551472 . 
Berre, L. 2000. Estimation of synoptic and meso scale forecast error covariances in a limited area model. Mon. Wea. Rev. 128, 644-667.

Bouttier, F. 1996. Application of Kalman filtering to numerical weather prediction. Proceedings of the 1996 ECMWF Seminar on Data Assimilation, 61-90.

Buizza, R. and Palmer, T. N. 1995. The singular-vector structure of the atmospheric global circulation. J. Atmos. Sci. 52, 1434-1456.

Courtier, P., Thépaut, J.-N. and Hollingsworth, A. 1994. A strategy for operational implementation of 4D-Var using an incremental approach. Q.J.R. Meteorol. Soc. 120, 1367-1388.

Cuxart, J., Bougeault, P. and Redelsperger, J.-L. 2000. A turbulence scheme allowing for mesoscale and large eddy simulations. Q. J. R. Meteorol. Soc. 126, 1-31.

Dee, D. P. 1995. On-line estimation of error covariance parameters for atmospheric data assimilation. Mon. Wea. Rev., 123, 1128-1145

Desroziers, G. and Ivanov, S. 2001. Diagnosis and adaptive tuning of information error parameters in a variational assimilation. $Q$. J.R. Meteorol. Soc. 127, 1433-1452.

Desroziers, G., Berre, L., Chapnic, B. and Poli, P. 2005. Diagnosis of observation, background and analysis error statistics in observation space. Q.J. R. Meteorol. Soc., in press.

Eady, E. T. 1949. Long waves and cyclone waves. Tellus 1, 33-52.

Evensen, G. 2003. The ensemble Kalman Filter: Theoretical formulation and practical implementation. Ocean Dynamics 53, 343-367.

Fisher, M. 1996. The Specification of Background Error Variances in the ECMWF Variational Analysis System. Proceedings of the 1996 ECMWF Seminar on Data Assimilation, 645-652.

Fisher, M. 1998. Development of a simplified Kalman Filter. ECMWF Tech. Mem. 260.

Gustafsson, N. 1981. A review of methods for objective analysis. In $D y$ namic Meteorology: Data Assimilation Methods, (eds. L. Bengtsson, M. Ghil and E. Källén), Springer Verlag, New York, 17-76.

Gustafsson, N., Berre, L., Hörnquist, S., Huang, X.-Y., Lindskog, M. and co-authors. 2001. Three-dimensional variational data assimilation for a limited area model. Part I: general formulation and the background error constraint. Tellus 53A, 425-446.

Hollingsworth, A. and Lönnberg, P. 1986. The statistical structure of short-range forecast errors as determined from radiosonde data. Part I: the wind field. Tellus 38A, 111-136.

Hoskins, B. J. and Valdes, P. J. 1990. On the existence of storm tracks. J. Atmos. Sci. 47, 1854-1864.

Houtekamer, P. L. and Mitchell, H. L. 1998. Data assimilation using an ensemble Kalman filter technique. Mon. Wea. Rev. 126, 796-811.

Houtekamer, P. L., Lefaivre, L., Derome, J., Ritchie, H. and Mitchell, H. L. 1996. A System simulation approach to ensemble prediction. Mon. Wea. Rev. 124, 1225-1242.
Ingleby, N. B. 2001. The statistical structure of forecast errors and its representation in The Met. Office Global 3-D Variational Data Assimilation Scheme. Q. J. R. Meteorol. Soc. 127, 209231.

Ingleby, N. B. and Lorenc, A. C. 1993. Bayesian quality control using multivariate normal distibutions. Q. J. R. Meteorol. Soc. 119, 11951225.

Lindskog, M., Gustafsson, N., Navascués, B., Mogensen, K. S., Huang, X.-Y. and co-authors. 2001. Three-dimensional variational data assimilation for a limited area model. Part II: observation handling and assimilation experiments. Tellus 53A, 447-468.

Lindskog, M., Salonen, K., Järvinen, H. and Michelson, D. B. 2004. Doppler radar wind data assimilation with HIRLAM 3D-Var. Mon. Wea. Rev. 5, 1081-1092.

Lindzen, R. S. and Farell, B. 1980. A simple approximate results for the maximum growth rate of baroclinic instabilities. J. Atmos. Sci. 37, $1648-1654$.

Lorenc, A. and Hammon, O. 1988. Objective quality control of observations using Bayesian methods. Theory and practical implementation. Q.J.R. Meteorol. Soc. 114, 515-543

Lynch, P. and Huang, X.-Y. 1992. Initialization of the HIRLAM model using a digital filter. Mon. Wea. Rev. 120, 1019-1034.

Parrish, D. F. and Derber, J. C. 1992. The National Meteorological Centre's spectral statistical interpolation analysis system. Mon. Wea. Rev. 120, 1747-1763.

Petterssen, S. 1956. Weather Analysis and Forecasting. 2nd Edition, Vol. I: Motion and Motion systems. McGraw-Hill, New York

Rabier, F., McNally, A., Andersson, E., Courtier, P., Undén, P. and coauthors. 1998. The ECMWF implementation of three-dimensional variational assimilation (3D-Var). Part II: structure functions. $Q . J$. R. Meteorol. Soc. 124, 1809-1830.

Sass, B. H., Nielsen, N. W., Jørgensen, J. U. and Amstrup, B. 1999. The Operational HIRLAM system at DMI. DMI Tech. Rep. no. 9921, 42 pp., October 1999. Available from DMI, Lyngbyvej 100, Copenhagen.

Savijärvi, H. 1989. Fast Radiation parameterization schemes for mesoscale and short-range forecast models. J. Appl. Meteor. 29, 437447.

Savijärvi, H. 1995. Error growth in a large numerical forecast system. Mon. Wea., Rev. 123, 212-221.

Sundqvist, H. 1993. Inclusion of ice phase of hydrometers in cloud parameterization for mesoscale and large scale models. Beitr. Phys. Atmosph. 66, 137-147.

Undén, P., Rontu, L., Järvinen, H., Lynch, P., Calvo, J. and co-authors. 2002. HIRLAM-5 Scientific Documentation, HIRLAM-5 Project, c/o Per Undén SMHI, SE-601 76 Norrköping, Sweden. 